Revista Brasileira de Agricultura Irrigada v.10, nº.1, p. 428 - 438, 2016

ISSN 1982-7679 (On-line)

Fortaleza, CE, INOVAGRI - http://www.inovagri.org.br

DOI: $10.7127 /$ rbai.v10n100347

Protocolo 347.16 - 14/08/2015 Aprovado em 04/02/2016

\title{
EFLUENTE TRATADO NA AGRICULTURA: ASPECTOS AGRONÔMICOS E SANITÁRIOS NO CULTIVO DO RABANETE
}

\author{
Paulo Eduardo Ferreira Mendes ${ }^{1}$, Reinaldo Gaspar Bastos ${ }^{2}$, Claudinei Fonseca Souza ${ }^{2}$
}

\begin{abstract}
RESUMO
Devido à crescente escassez de fontes hídricas para irrigação, o efluente tratado tem-se tornado cada vez mais interessante por sua viabilidade agronômica, desde que usada de forma planejada e baseada em índices técnicos desenvolvidos para tal objetivo. Esta pesquisa avaliou a influência da qualidade da água de irrigação no estado nutricional e produção em dois ciclos do rabanete (Raphanus sativus L.) cv. Crimson Giant submetido a duas fontes de água, assim como as alterações nos atributos químicos do solo e o risco de contaminação por coliformes totais e E. coli. O experimento foi conduzido em um delineamento inteiramente casualizado, com dois tratamentos: água de abastecimento e efluente tratado, com quatro repetições. A efluente tratado não interferiu no estado nutricional e produção do rabanete; o efluente eleva o teor de macronutrientes no solo (P e K), a razão de adsorção de sódio e a percentagem de sódio trocável do solo, embora sem risco de salinização e sodificação; o rabanete não apresentou padrões sanitários adequados ao consumo humano in natura.
\end{abstract}

Palavras-chave: fertilidade do solo, qualidade microbiológica, reuso, E. coli.

\section{TREATED EFFLUENT IN AGRICULTURE: AGRONOMIC AND SANITARY ASPECTS IN RADISH CULTIVATION}

\begin{abstract}
Due to increasing irrigation water scarcity, treated effluent is becoming a more attractive showing agronomic feasibility, if based on specifical technical criteria. This research evaluated the influence of irrigation water quality in nutritional status and production in two cycles Radish (Raphanus sativus L.) cv. Crimson Giant subjected to two sources of water, as well as changes in soil chemical properties and contamination risk for total coliforms and $E$. coli. The experiment was conducted in a completely randomized design with two treatments: water supply and treated effluent, with four replications. Treated wastewater did not influence radish nutritional and production; treated effluent increased macronutrients (P and K), sodium adsorption ratio and exchangeable sodium percentage, but without salinization and sodification risk; radish didn't showed sanitary conditions to in natura human consumption.
\end{abstract}

\footnotetext{
${ }^{1}$ Mestre em Agricultura e Ambiente, PPGAA - UFSCar, Araras, SP, mendes-pauloeduardo@uol.com.br.

${ }^{2}$ Professor, Centro de Ciências Agrárias, UFSCar, Araras, SP, reinaldo@cca.ufscar.br, cfsouza@cca.ufscar.br.
} 
Keywords: soil fertility, microbial quality, reuse, E. coli.

\section{INTRODUÇÃO}

O solo deve ser apto no suprimento dos nutrientes requeridos pelas plantas em doses e momento adequados. A água via irrigação e precipitação é o recurso que atua como solvente, disponibilizando os minerais à zona radicular. A agricultura é a atividade que demanda maior consumo de água, utilizando-se cerca de $80 \%$ do recurso hídrico na prática da irrigação (Khurana \& Singh, 2012).

No entanto, a redução e/ou escassez de fontes hídricas de qualidade, tem levado países e centros de pesquisa a repensar o emprego de águas de qualidade inferior na agricultura. Citase, ainda, a alta produção de esgotos, os fatores climáticos, a urbanização, a expansão agrícola, a industrialização e o desenvolvimento socioeconômico (Ribeiro et al., 2013) como fatores propulsores do reuso agrícola da água no Brasil e em outros países.

$\mathrm{O}$ uso de efluentes tratados em cultivos agrícolas auxilia no controle da poluição ambiental, além de disponibilizar água e nutrientes para as culturas, mostrando-se uma prática viável. Para Ribeiro et al., (2013), a descarga controlada de efluente tratado via sistema de irrigação, visa suportar o crescimento de culturas e é dependente de fatores inerentes ao solo, cultura, aspectos sanitários e ambientais.

Oliveira et al., (2013), avaliando a produção de moranga irrigada com efluente tratado, observaram diferença significativa na produtividade, porém sem comprometer as características físico-químicas dos frutos e, sobretudo, a qualidade sanitária dos mesmos. Já Bakhsh \& Hassan (2005), concluíram que o rabanete, irrigado com efluentes tratados, em contato direto com o mesmo em um ciclo produtivo, requereu menos uso de adubos químicos sintéticos, além do custo de aplicação dos mesmos diminuir, em comparação a outras fontes de água.

$\mathrm{O}$ rabanete enquadra-se como uma das culturas com menor tolerância aos sais, apresentando moderada sensibilidade aos mesmos, com semi-tolerância ao sódio trocável e moderada sensibilidade ao boro (1,0-2,0 mg $\mathrm{L}^{-1}$ ). Bakhsh \& Hassan (2005) verificaram que água de reuso tratada com desequilíbrio de nutrientes ( $\mathrm{N}, \mathrm{P}, \mathrm{Na}$ e $\mathrm{Ca}$ ) comprometeu o estádio de maturação do rabanete, reduzindo substancialmente a produção.

Desta forma, esse trabalho avaliou a influência da qualidade da água de irrigação no estado nutricional e produção do rabanete cv. Crimson Giant submetido a duas fontes de água, assim como as alterações nos atributos químicos do solo e contaminação sanitária do rabanete e do solo.

\section{MATERIAL E MÉTODOS}

O experimento foi conduzido em um ambiente protegido anexo à Estação de Tratamento de Esgoto, no Centro de Ciências Agrárias da Universidade Federal de São Carlos, município de Araras-SP. As coordenadas geográficas do local são: latitude $22^{\circ} 18$ ' $53,23^{\prime \prime}$ S e longitude $47^{\circ} 23^{\prime} 00,91^{\prime \prime} \mathrm{W}$ e altitude média de $700 \mathrm{~m}$.

O clima da região, segundo a classificação climática de Köppen, é do tipo Cwa, mesotérmico, com verões quentes e úmidos, além de precipitação e temperatura médias de $1400 \mathrm{~mm}$ e $22^{\circ} \mathrm{C}$, respectivamente.

O experimento foi conduzido em dois ciclos da cultura do rabanete, para os quais foi planejado e conduzido um delineamento inteiramente casualizado com dois tratamentos e quatro repetições, totalizando oito parcelas experimentais; cada parcela experimental possuía a dimensão de 1,5 m de largura e 2,10 $\mathrm{m}$ de comprimento e quatro linhas de rabanete, sendo que a área útil às duas internas medindo $1,08 \mathrm{~m}^{2}$.

Os tratamentos testados foram: $\mathrm{AB}$ - água de abastecimento e ET - efluente tratado. A água de abastecimento e a água de reuso tratada foram provenientes do sistema de abastecimento de água (poço artesiano) e da 
ETE - Estação de Tratamento de Esgoto

(Figura 1), respectivamente.

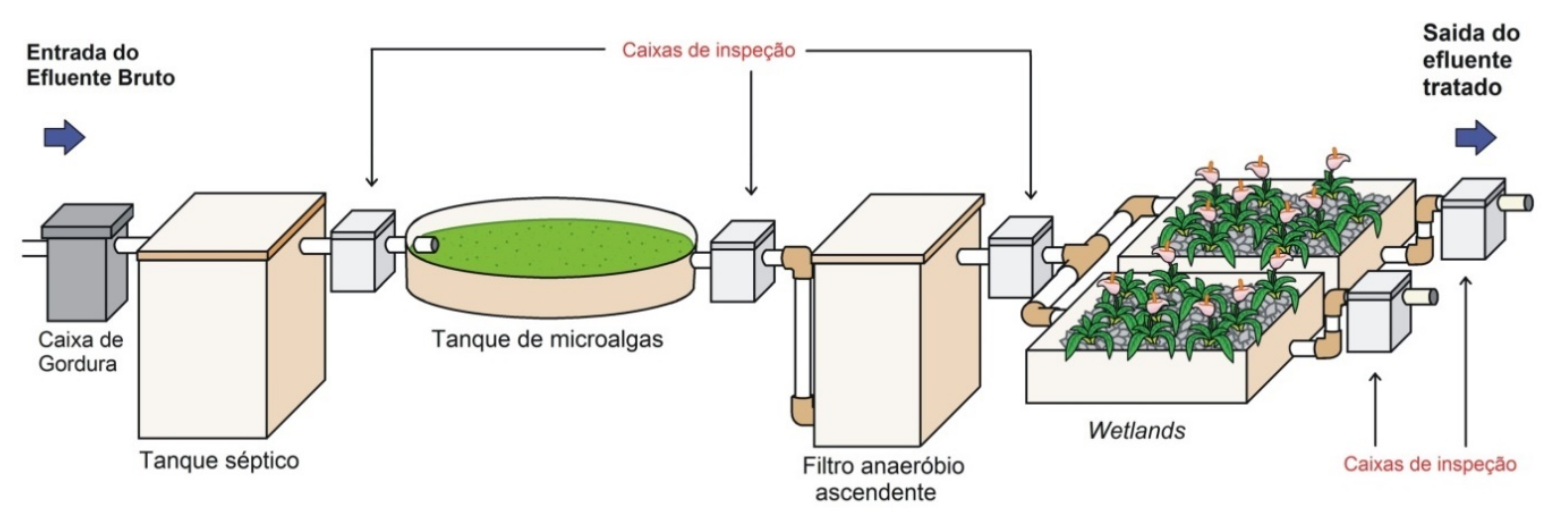

Figura 1. Ilustração esquemática da ETE instalada no Campus Araras da UFSCar.

O rabanete cv. Crimson Giant cultivado teve contato direto com o solo irrigado com efluente tratado e água de abastecimento. Realizou-se a semeadura direta em canteiros, os quais foram irrigados, igualmente, a fim de garantir a uniformidade de crescimento até o $5^{\circ}$ dia após a germinação. $\mathrm{O}$ espaçamento utilizado foi de $0,30 \times 0,15 \mathrm{~m}$ entre linhas e plantas, ocorrendo o desbaste das mudas quando apresentavam o primeiro par de folhas. Realizou-se a colheita quando as plantas completaram 30 dias após a semeadura.

O solo da área experimental é classificado como Latossolo Vermelho (LV), eutrófico, textura argilosa e relevo suave ondulado, do qual se coletou amostra (0-0,2 m) para análises (EMBRAPA, 2009) química e física.

Do ponto de vista físico, o solo apresentava textura franco-argilosa, densidade (1,3 $\left.\mathrm{kg} \mathrm{dm}^{-3}\right)$, além de conter, em média, a seguinte composição: argila, 37\%; areia total, $41 \%$ (areia grossa, 20\%; areia fina, 21\%); e, silte, $22 \%$.

Conforme a análise do solo e recomendações do Boletim Técnico 100 do IAC (Trani et al., 1997), não houve a necessidade de calagem. Aplicou-se, na adubação química de plantio, $20 \mathrm{~kg} \mathrm{ha}^{-1}$ de $\mathrm{N}$ (nitrato de cálcio - $\left.\mathrm{Ca}\left(\mathrm{NO}_{3}\right)_{2}\right), 240 \mathrm{~kg} \mathrm{ha}^{-1}$ de $\mathrm{P}$ (superfosfato simples) e $120 \mathrm{~kg} \mathrm{ha}^{-1}$ de $\mathrm{K}$ (cloreto de potássio - $\mathrm{KCl}$ ) em ambos os tratamentos.

Para água de abastecimento, efetuou-se a adubação de cobertura, conforme recomendação de Trani et al., (1997), para a qual aplicou-se via fertirrigação, $60 \mathrm{~kg} \mathrm{ha}^{-1}$ de $\mathrm{N}$ e $30 \mathrm{~kg} \mathrm{ha}^{-1}$ de $\mathrm{K}$, respectivamente. Para a adubação no tratamento efluente tratado, subtraiu-se dos valores de $\mathrm{N}$ e $\mathrm{K}$ recomendados por Trani et al. (1997), a quantidade aportada destes nutrientes pela água de reuso tratada $\left(10,68 \mathrm{mg} \mathrm{L}^{-1} \mathrm{~N}\right.$ e $\left.17,94 \mathrm{mg} \mathrm{L}{ }^{-1} \mathrm{~K}\right)$. Assim, a fertirrigação foi efetuada com as doses de 50,5 $\mathrm{kg} \mathrm{ha}^{-1}$ de $\mathrm{N}$ e $14 \mathrm{~kg} \mathrm{ha}^{-1}$ de K. As doses foram parceladas e aplicadas aos 7, 14 e 21 dias após a semeadura, conforme a recomendação anterior. Após esse período, aplicou-se apenas água de irrigação de forma a repor a demanda evapotranspirométrica.

Para a aplicação de água de abastecimento e efluente tratado, utilizou-se o sistema de irrigação localizada por gotejamento, composto por unidade de controle (conjunto motobomba com $0,5 \mathrm{cv}$ de potência, filtro com 125 mícrons e manômetros), gotejadores com vazão média de $4,0 \mathrm{~L} \mathrm{~h}^{-1}$ e espaçados de $0,30 \mathrm{~m}$ entre si, uma linha primária e duas linhas de derivação para cada tipo de água, de modo a não permitir a mistura das mesmas.

Determinou-se a frequência de irrigação e a quantidade de água a ser aplicada a partir da variação dos valores médios diários da umidade volumétrica do solo $(\Theta)$ e da correspondente à capacidade de campo (CC). A umidade foi obtida por meio de sensores FDR, instaladas a 0-0,10 m e 0-0,20 $\mathrm{m}$ de profundidade e programada para realizar leituras a cada $5 \mathrm{~min}$. 
Estudou-se a curva característica do solo, a fim de determinar o seu ponto ótimo de umidade, a ser mantido para atendimento das necessidades do rabanete e manutenção do solo na CC, que foi determinada e equivalente, para a profundidade efetiva do sistema radicular do rabanete $(0-20 \mathrm{~cm})$, a um potencial mátrico de $3 \mathrm{JN}^{-1}$ (1/3 de atm, $33 \%$ ou $0,33 \mathrm{~m}^{3} \mathrm{~m}^{-3}$ ).

Assim, o volume de reposição da água foi calculado, conforme Eq. 1:

$$
\text { LLI }=\frac{\text { Ucc }- \text { Uobs }}{10} \times \mathrm{ds} \times \mathrm{Z}
$$

\section{Em que:}

LLI - lâmina líquida de irrigação (mm)

$\mathrm{U}_{\mathrm{cc}}$ - umidade na capacidade de campo (\% em massa)

$\mathrm{U}_{\text {obs }}$ - umidade observada (\% em massa)

ds - densidade do solo $\left(\mathrm{g} \mathrm{cm}^{-3}\right)$

$\mathrm{Z}$ - profundidade efetiva do sistema radicular (cm)

É importante ressaltar que para a irrigação dos canteiros, transformou-se a LLI em volume ( $\mathrm{L} \mathrm{m}^{-2}$ ) multiplicando-se a LLI pela área do canteiro $\left(3,15 \mathrm{~m}^{2}\right)$. Usou-se o turno de rega diário e a quantidade média de água exigida por planta foi de $3,5 \mathrm{~mm} \mathrm{~d}^{-1}$.

A coleta de amostras para análise do efluente tratado e da água de abastecimento foi semanal. As análises físico-químicas da ET foram realizadas no Laboratório de Microbiologia Aplicada e Controle, conforme metodologias propostas por APHA (2005) e cujos resultados e faixa de concentração permitiram o reuso agrícola, conforme IT $n^{0}$ 32/06 (CETESB, 2006). Procedeu-se a determinação do NMP de E. coli utilizando-se o método enzimático (sistema Colilert da IDEXX; referência à marca registrada não constitui endosso por parte dos autores). A estimativa de coliformes foi expressa em número mais provável (NMP) em 100 mL de água.

Efetuou-se a coleta, acondicionamento, identificação e envio de tecido foliar da área útil ao laboratório, para a determinação de nutrientes, consoante recomendações de EMBRAPA (2009).
Transcorrido o período experimental, coletaram-se amostras de solo $(0-0,20 \mathrm{~m})$ de cada unidade experimental e submeteram-nas às análises químicas, conforme recomendação de EMBRAPA (2009). As variáveis de solo analisadas foram: $\mathrm{pH}, \mathrm{P}, \mathrm{K}^{+}, \mathrm{Ca}^{++}, \mathrm{H}+\mathrm{Al}, \mathrm{Na}^{+}$, saturação por bases (V\%), porcentagem de sódio trocável (PST) e a razão de adsorção de sódio (RAS). A PST foi obtida conforme a Eq. 2:

$$
\text { PST }=\text { Na trocável } \frac{100}{\text { CTC }}
$$

Em que:

PST - porcentagem de sódio trocável (\%)

CTC - capacidade de troca de cátions $\left(\mathrm{mmol}_{\mathrm{C}} \mathrm{dm}^{-3}\right)$

Aos 30 DAS, mensurou-se a produção de raiz da área útil após as plantas serem colhidas e conduzidas ao laboratório. Posteriormente, as raízes foram seccionadas junto ao colo, lavadas e secadas com papel toalha para, finalmente, serem pesadas em balança analítica (precisão 0,1 g); calculou-se o peso médio das raízes de cada tratamento. Coletaram-se ainda amostras de solo (0-0,20 m) e rabanete entre plantas nas linhas de plantio, dentro da área útil de cada parcela, no dia da colheita.

Posteriormente, as amostras foram encaminhadas ao Laboratório de Microbiologia Aplicada e Controle para as análises microbiológicas, seguindo a metodologia descrita em APHA (2005). As raízes foram seccionadas com bisturi e pinça estéreis. Posteriormente, acondicionou-se em erlenmeyers previamente esterilizados, contendo solução peptonada $0,1 \%$. A seguir, 10 g da amostra das raízes foram utilizados para quantificar a bactéria E. coli, segundo a metodologia adaptada de APHA (2005). Foi adotada a metodologia das placas Petrifilm da 3M (referências à marca registrada não constituem endosso por parte dos autores) para coliformes totais e termotolerantes (Escherichia coli).

De posse dos resultados sobre padrões microbiológicos do rabanete, os mesmos foram comparados com a resolução ANVISA $n^{\circ}$ 
12/2001 (Brasil, 2001). Os efeitos dos tipos de água (qualitativos) sobre os parâmetros nutricionais, químicos e sanitários do solo foram verificados a partir da análise de variância, os resultados colhidos foram submetidos ao teste $\mathrm{F}$ a $5 \%$ de significância e as médias dos tratamentos comparadas pelo teste de Tukey $(\mathrm{p}<0,05)$. Para realização das análises estatísticas, utilizou-se o programa estatístico (ASSISTAT, 2014). Apesar do grau de liberdade não ser ideal (Steel et al. 1997), a análise estatística é robusta considerando que o nível de significância adotado foi 5 \%, situação onde os dados desta natureza possuem pequena variância (Zar, 2010).

\section{RESULTADOS E DISCUSSÃO}

Os resultados referentes à caracterização química da água de abastecimento e do efluente tratado em termos de $\mathrm{pH}, \mathrm{CE}$, potássio, sódio, cálcio, sólidos total, coliformes totais, E. coli e o permitido pela resolução CONAMA n. 357/05 (BRASIL, 2005), podem ser observados na Tabela 1.

Tabela 1. Caracterização química e microbiológica da AB, do ET e da Res. Conama n 357/05 para Classe 1.

\begin{tabular}{lcccc}
\hline \multicolumn{1}{c}{ Parâmetro } & Unidade & $\mathrm{AB}$ & $\mathrm{ET}$ & Conama 357/05 \\
\hline $\mathrm{pH}$ & - & $7,36 \pm 0,47$ & $7,54 \pm 0,20$ & $6,0-9,0$ \\
$\mathrm{CE}$ & $\mathrm{dS} \mathrm{m}^{-1}$ & $0,20 \pm 0,031$ & $0,35 \pm 0,050$ & - \\
$\mathrm{K}^{+}$ & $\mathrm{mg} \mathrm{L}^{-1}$ & $6,76 \pm 4,29$ & $17,94 \pm 5,27$ & - \\
$\mathrm{N}$ total & $\mathrm{mg} \mathrm{L}^{-1}$ & $0,12 \pm 0,10$ & $10,68 \pm 1,29$ & - \\
$\mathrm{Ca}^{++}$ & $\mathrm{mg} \mathrm{L}^{-1}$ & $2,66 \pm 0,56$ & $8,56 \pm 1,56$ & - \\
$\mathrm{Na}^{+}$ & $\mathrm{mg} \mathrm{L}^{-1}$ & $18,38 \pm 0,52$ & $31,38 \pm 0,97$ & - \\
Sólidos Totais & $\mathrm{mg} \mathrm{L}^{-1}$ & $104,33 \pm 6,80$ & $216,25 \pm 27,76$ & 500,0 \\
Coliformes Totais & $\mathrm{NMP} 100 \mathrm{~mL}^{-1}$ & $<10^{5}$ & $<10^{5}$ & - \\
E. coli & $\mathrm{NMP} 100 \mathrm{~mL}^{-1}$ & $<10^{3}$ & $<10^{3}$ & - \\
\hline
\end{tabular}

Nota: CE - condutividade elétrica; K - Cátion Potássio; $\mathrm{N}$ total - Nitrogênio total; Ca $^{++}$- Cátion Cálcio

Analisando-se as características físicoquímicas do efluente e da água de abastecimento (Tabela 1) com aqueles estipulados pela resolução CONAMA n. 357/05 (BRASIL, 2005), para águas de classe l, destinadas “à irrigação de hortaliças que são consumidas cruas e de frutas que se desenvolvam rentes ao solo e que sejam ingeridas cruas sem remoção de película” (rabanete, p.ex.) tem-se que os valores se enquadram no estipulado pela resolução.

Quanto aos valores de CE e ao $\mathrm{Na}^{+}$, os valores obtidos são inferiores ao que determina a IT $n^{0}$ 32/2006 (CETESB, 2006), que orienta valores para reuso agrícola de efluentes domésticos (2,9 dS m ${ }^{-1}$ e 69,0 $\mathrm{mg} \mathrm{L}^{-1}$, respectivamente). Os valores de $\mathrm{CE}$ foram inferiores ainda aos preconizados por Ayers e Westcot (1999), que afirmam que valores inferiores a $0,70 \mathrm{dS} \mathrm{m}^{-1}$ não apresentam qualquer grau de restrição para a irrigação de culturas agrícolas.

$\mathrm{O} \mathrm{pH}$ do efluente encontrou-se próximo à neutralidade (Tabela 1), mostrando adequado ao cultivo agrícola. Os teores de $\mathrm{N}$ e $\mathrm{K}$ presentes no efluente tratado (Tabela 1) evidenciam aportes nutricionais pouco significativos ao rabanete, mas sem comprometer o equilíbrio nutricional. Tal resultado concorda com o encontrado por Zavadil (2009), que usou efluente tratado como fonte de água em rabanete, cenoura e alface.

Comparando-se o teor de sólidos totais com os $500,00 \mathrm{mg} \mathrm{L}^{-1}$, preconizado pela IT $\mathrm{n}^{\circ}$ 32/2006 (CETESB, 2006), verifica-se que os valores estão abaixo do estipulado, não apresentando qualquer restrição ao reuso agrícola. Convém registrar a ausência de entupimento dos emissores a irrigação por gotejamento nesse experimento. 
A contagem de coliformes totais excedeu os limites permitidos pela legislação brasileira para reuso agrícola tanto para água de abastecimento como efluente, que é de, no máximo, $10^{3}$ NMP $100 \mathrm{~mL}^{-1}$. Acredita-se que parte da contaminação microbiana verificada deve se refletir no rabanete irrigado mesmo que a estação piloto apresente remoção de patógenos. Convém ressaltar que o sistema de tratamento e reuso não foi projetado para funcionar como uma lagoa de maturação, ou seja, manter elevados tempos de detenção, elevado pH e concentração de oxigênio dissolvido (Von Sperling, 1996). Nessas condições, as lagoas devem atingir elevadas eficiências na ordem de 99,99\% de remoção de coliformes.

Os valores inerentes aos atributos químicos, PST e RAS do solo podem ser observados na Tabela 2, bem como alguns atributos químicos do solo recomendado para o rabanete de acordo com Trani et al. (1997).

Tabela 2. Características químicas do solo no início e final do experimento e a recomendação segundo Trani et al. (1997).

\begin{tabular}{|c|c|c|c|c|c|}
\hline Variável & Trat. & Início & Final & C.V \% & Trani et al., (1997) \\
\hline \multirow{2}{*}{$\mathrm{pH}\left(\mathrm{CaCl}_{2}\right)$} & $\mathrm{AB}$ & 5,7 & $6,25 \mathrm{a}$ & \multirow{2}{*}{0,68} & \multirow{2}{*}{$5,5-6,0$} \\
\hline & ET & 5,5 & $5,80 \mathrm{~b}$ & & \\
\hline \multirow{2}{*}{$\mathrm{P}$ (resina), $\mathrm{mg} \mathrm{dm}^{-3}$} & $\mathrm{AB}$ & 30 & $33,50 \mathrm{a}$ & \multirow{2}{*}{53,26} & \multirow{2}{*}{$>120,00$} \\
\hline & $\mathrm{ET}$ & 28 & $36,75 \mathrm{a}$ & & \\
\hline \multirow{2}{*}{$\mathrm{K}^{+}, \mathrm{mmol}_{\mathrm{C}} \mathrm{dm}^{-3}$} & $\mathrm{AB}$ & 2,3 & $4,50 \mathrm{a}$ & \multirow{2}{*}{11,23} & \multirow{2}{*}{$3,1-6,0$} \\
\hline & ET & 3,0 & $4,10 \mathrm{a}$ & & \\
\hline \multirow{2}{*}{$\mathrm{Ca}^{++}, \mathrm{mmol}_{\mathrm{C}} \mathrm{dm}^{-3}$} & $\mathrm{AB}$ & 76 & $64,00 \mathrm{a}$ & \multirow{2}{*}{11,10} & \multirow{2}{*}{$>7,0$} \\
\hline & ET & 76 & $54,75 \mathrm{a}$ & & \\
\hline \multirow{2}{*}{ V\% } & $\mathrm{AB}$ & 79 & $79,75 \mathrm{a}$ & \multirow{2}{*}{4,58} & \multirow{2}{*}{ 60-80 (bom) } \\
\hline & ET & 77 & $77,25 \mathrm{a}$ & & \\
\hline \multirow{2}{*}{$\mathrm{H}+\mathrm{Al}, \mathrm{mmol}_{\mathrm{c}} \mathrm{dm}^{-3}$} & $\mathrm{AB}$ & 26 & $20,75 \mathrm{a}$ & \multirow{2}{*}{14,79} & \multirow{2}{*}{-} \\
\hline & ET & 29 & $23,25 \mathrm{a}$ & & \\
\hline \multirow{2}{*}{$\mathrm{Na}^{+}, \mathrm{mmol}_{\mathrm{C}} \mathrm{dm}^{-3}$} & $\mathrm{AB}$ & 0,14 & $1,57 \mathrm{~b}$ & \multirow{2}{*}{14,47} & \\
\hline & ET & 0,29 & $2,04 \mathrm{a}$ & & \\
\hline \multirow{2}{*}{ PST, \% } & $\mathrm{AB}$ & 0,11 & $1,76 \mathrm{~b}$ & \multirow{2}{*}{23,88} & \multirow{2}{*}{-} \\
\hline & $\mathrm{ET}$ & 0,23 & $3,51 \mathrm{a}$ & & \\
\hline \multirow{2}{*}{$\operatorname{RAS}\left(\mathrm{mmol}_{\mathrm{C}} \mathrm{L}^{-1}\right)^{1 / 2}$} & $\mathrm{AB}$ & 0,020 & $0,10 \mathrm{~b}$ & \multirow{2}{*}{24,56} & \multirow{2}{*}{-} \\
\hline & ET & 0,042 & $0,19 \mathrm{a}$ & & \\
\hline
\end{tabular}

Nota: P (resina) - Fósforo pelo método de extração em resina; K - Cátion Potássio; $\mathrm{Ca}^{++}$- Cátion Cálcio; V\% - Saturação por bases; $\mathrm{H}+\mathrm{Al}$ - Hidrogênio + Alumínio; $\mathrm{Na}^{+:}$Cátion sódio; PST - porcentagem de sódio trocável; RAS - razão de adsorção de sódio; C.V - coeficiente de variação. Médias seguidas por letras iguais na coluna entre AB e ET não diferem entre si, a 0,05 de significância, pelo teste de Tukey.

Quanto ao atributo $\mathrm{pH}$, o tratamento com água de abastecimento diferiu estatisticamente entre si, havendo acréscimo do mesmo em ambos os tratamentos (Tabela 2).

Estes resultados diferem-se dos obtidos por Barreto et al., (2013), os quais não constataram alterações no $\mathrm{pH}$ do solo irrigado com efluente tratado. $\mathrm{O} \mathrm{pH}$ encontrado denota acidez baixa e atende às exigências do rabanete, cujo ideal está entre 5,5 e 6,0 (Trani et al., 1997).
Quanto ao fósforo e potássio, não foi observada diferença estatística entre os tratamentos, mas constatou-se acréscimo em seus valores. Os resultados obtidos estão coerentes com Barreto et al., (2013), que também observaram acréscimos de fósforo e potássio no solo após aplicação de efluente tratado.

O teor do $\mathrm{Na}^{+}$trocável (Tabela 2) no tratamento com efluente tratado diferiu estatisticamente para o tratamento com água de abastecimento e, comparado à análise inicial do 
solo, apresentou elevação em ambos os tratamentos, mesmo resultado observado por Barreto et al., (2013) em seu experimento.. O sódio presente na água de irrigação favorece a elevação da porcentagem de sódio trocável (PST) no solo, afetando as propriedades físicas e químicas e dificultando a atividade da água a ser utilizada pela planta (Sandri et al., 2009).

Mesmo que discretamente era esperada essa elevação no tratamento com efluente tratado, devido ao fato do mesmo conter sais solúveis, havendo a sua adição à solução do solo. Contudo, os efeitos potenciais do sódio $\left(\mathrm{Na}^{+}\right)$são ligeiramente menores quando a relação $\mathrm{Ca}^{2+} / \mathrm{Mg}^{2+}$ na água de irrigação é $>1$. Logo, o valor da RAS é ligeiramente menos danoso quando tal proporção é $>1$, além de que quanto mais alta for essa proporção, menor será o perigo do efeito da RAS (Ayers e Westcot, 1999).

Com relação à porcentagem de sódio trocável (PST), notou-se um aumento nos valores de ambos os tratamentos (Tabela 2). O tratamento que se aplicou efluente tratado apresentou maiores valores com relação a PST, mudando de $0,23 \%$ para $3,51 \%$ e apresentando diferença estatística significativa. Esses valores estão conforme o recomendado por (CETESB, 2006), que considera solo apto ao reuso agrícola de efluente doméstico aquele cuja PST é menor que 6\%, já solo com PST < 7\% é classificado como normal. Para Walker \& Bernal (2008), quando os níveis de PST do solo atingem 15\%, o mesmo é considerado sódico, afetando os seus atributos estruturais e hidráulicos.

Os cálculos da RAS, anterior à aplicação do efluente tratado, apontava para o valor de $0,042\left(\mathrm{mmol}_{\mathrm{C}} \mathrm{L}^{-1}\right)^{1 / 2}$. Já ao final do experimento o valor elevou-se para $0,19\left(\mathrm{mmol}_{\mathrm{C}} \mathrm{L}^{-1}\right)^{1 / 2}$, diferindo estatisticamente do tratamento com água de abastecimento (Tabela 2). Ressalta-se, contudo, que quanto ao risco de sodificação, os valores são enquadrados na classe 1 (baixo risco).

Esse quadro é reforçado por Medeiros et al. (2005) que mostram que o solo que recebeu efluente tratado, elevou a RAS tanto utilizando água limpa quanto efluente. Paralelo ao aumento da RAS acompanhou-se também aumento na CE do solo. Sabe-se que o solo, para estar em condição de dispersão, deverá apresentar altos valores de RAS e baixa CE. Tal fato não foi observado em nenhum dos tratamentos.

Os resultados da análise foliar da cultura comparados com os valores preconizados pela literatura científica para o rabanete estão contidos na Tabela 3.

Tabela 3. Teores foliares de N, P, K, Ca, Mg e S, comparado à faixa recomendada pela literatura.

\begin{tabular}{ccccccc}
\hline \multirow{2}{*}{ Trat. } & $\mathrm{N}$ & $\mathrm{P}$ & $\mathrm{K}$ & $\mathrm{Ca}$ & $\mathrm{Mg}$ & $\mathrm{S}$ \\
\cline { 2 - 7 } & & & \multicolumn{5}{c}{$\mathrm{g} \mathrm{kg}^{-1}$} \\
AB & 58,00 & 4,40 & 42,80 & 31,00 & 4,00 & 5,90 \\
ET & 68,50 & 5,60 & 41,60 & 34,60 & 4,30 & 6,80 \\
Trani et al., (1997) & $30-60$ & $3-7$ & $40-75$ & $30-45$ & $5-12$ & -
\end{tabular}

Nota: N - Nitrogênio; P - Fósforo; K - Potássio; Ca - Cálcio; Mg - Magnésio; S - Enxofre.

Verifica-se que os teores dos nutrientes enquadram-se na faixa recomendada por Trani et al., (1997), exceto o N. Porém, o mesmo encontra-se dentro dos valores de tolerância e, em momento algum ao longo do experimento, as plantas apresentaram quaisquer indícios visuais de fitotoxidez por $\mathrm{N}$ que pudessem comprometer sua fisiologia.

$\mathrm{O}$ reuso agrícola deste efluente, complementado com a adubação mineral, poderia suprir as demandas nutricionais das culturas, pois há disponibilização dos nutrientes apenas com a mineralização do material orgânico. Apesar disto, o aporte de nutrientes às culturas pelo efluente está condicionado à sua composição e lâmina aplicada (Sandri et al., 2009).

Quanto à produção de raízes, não houve diferença significativa entre a água de abastecimento e efluente tratado, apresentando 13,24 e 16,88 g planta $^{-1}$, respectivamente. 
Essa produção contrasta com a obtida por Pereira \& Piedade (2004), que cultivando rabanete em cultivo protegido sob outra condição edafoclimática, obtiveram raízes com peso médio de até 39,95 g.

Teófilo et al., (2009) são unânimes ao afirmarem que as plantas, notadamente as hortaliças-raízes, tal como o rabanete, inicialmente destinam os fotoassimilados produzidos à formação das estruturas da parte aérea, a fim de aumentar a área foliar. Porém, a partir de dado momento, há uma tendência da maior parte dos fotoassimilados produzidos ser destinada às estruturas de reservas (drenos), que para o rabanete é a raiz.

A contaminação microbiológica de culturas irrigadas por efluente tratado é o principal risco do reuso agrícola quando a eficiência de desinfecção dos sistemas de tratamento não é alcançada.

Baumgartner et al. (2007) encontraram coliformes totais com valores superiores a 5000 NMP $100 \mathrm{~mL}^{-1}$ em águas de efluentes de lagoas de estabilização de dejetos de suínos. Takayanagui et al. (2006) afirmam que a contaminação de hortaliças ocorre de modo geral na horta por meio da utilização de água de irrigação ou adubos inadequados, além da manipulação nos pontos de venda e transporte dos produtos.

Os valores encontrados por Takayanagui et al. (2006) nos efluentes tratados, de abastecimento e do produtor rural apresentaram valores de coliformes totais e coliformes a $45^{\circ} \mathrm{C}$ que poderiam causar algum tipo de contaminação nas folhas de alface devido ao manejo da irrigação adotada.

As bactérias entéricas do gênero Escherichia configuram-se num parâmetro indicativo mais específico, pois são restritas ao trato intestinal de animais de sangue quente. A resolução ANVISA n. 12/01 (Brasil, 2001) delimita um máximo de $10^{2}$ coliformes termotolerantes por grama para raízes, tubérculos e similares consumidos in natura.

Assim, conforme a Tabela 4, a sua presença em amostras de rabanete tanto para efluente tratado como para água de abastecimento indicou contaminação acima do permitido, exigindo tratamento complementar prévio a comercialização.

Cabe ressaltar que, de acordo com a Tabela 1, os valores de coliformes totais excederam os limites permitidos pela legislação brasileira para água de abastecimento e efluente tratado e que o reflexo disto foi a contaminação observada no rabanete e solo.

Dentre a provável causa da contaminação, pode-se sugerir a água de irrigação decorrente de eventual deficiência no sistema de tratamento, visto que as etapas de tratamento na ETE não foram efetivamente projetadas para a remoção de patógenos. Além disso, o contato direto do tubérculo do rabanete com a água de irrigação propicia a contaminação patogênica.

Sendo assim, se considerarmos em termos de massa para fins de comparação, pode-se estimar que a estação de tratamento de esgoto tivesse reduzido à contagem em torno de dois ciclos logaritmos $\left(10^{4}\right.$ a $\left.10^{2} \mathrm{NMP}^{-1}\right)$, ou seja, 99\% de remoção de coliformes. Embora isto indique uma eficiência aceitável, foi insuficiente devido às características das amostras brutas na entrada do tratamento.

Tabela 4. Perfil microbiológico do rabanete e do solo, nos diferentes tratamentos.

\begin{tabular}{ccccc}
\hline \multirow{2}{*}{ Tratamentos } & \multicolumn{2}{c}{ Coliformes totais $\left(10^{2} \mathrm{NMP} \mathrm{g}^{-1}\right)$} & \multicolumn{2}{c}{ E. coli $\left(10^{7} \mathrm{UFC} \mathrm{g}^{-1}\right)$} \\
\cline { 2 - 5 } & Rabanete & Solo & Rabanete & Solo \\
\hline AB & $3,16 \mathrm{a}^{1}$ & $15,49 \mathrm{a}$ & $5,56 \mathrm{a}$ & $2,88 \mathrm{a}$ \\
ET & $3,91 \mathrm{a}$ & $2,91 \mathrm{a}$ & $8,61 \mathrm{a}$ & $4,18 \mathrm{a}$ \\
$\mathrm{DMS}$ & 5,22 & 26,53 & 14,1 & 7,27 \\
$\mathrm{CV} \%$ & 85,24 & 166,64 & 11,45 & 11,90
\end{tabular}

Nota: ${ }^{1}$ Médias seguidas por letras iguais não diferem entre si, a 0,05 de significância, pelo teste de Tukey. 
Resultados distintos foram obtidos por Oliveira et al. (2013) que registraram a presença de coliformes totais em níveis abaixo dos limites mínimos admitido pela legislação sanitária irrigando moranga com esgoto tratado sob sistema de irrigação por gotejamento.

Quanto à condição sanitária do solo, inúmeros fatores interferem na sobrevivência dos patógenos, tais como tempo de contato solo-efluente (Rocha et al., 2003); sistema de irrigação (Varallo et al., 2011); luz solar, pH, temperatura, concentração de matéria orgânica e consumo dos substratos por outros microorganimos e umidade relativa do ar.

Com relação a $E$. coli sugere que, devido à presença destes micro-organismo em ambos os tratamentos, houve um rápido crescimento no solo, levando a contaminação do rabanete via contato direto com os tubérculos. Estes resultados são discordantes com Abreu et al., (2010) que, seguindo recomendação de APHA (2005), compararam diferentes fontes de adubação orgânica com a adubação mineral e não verificaram contaminação por coliformes termotolerantes em amostras de solo, atribuindo tal fato à água de irrigação.

\section{CONCLUSÕES}

1. O uso de efluente tratado não comprometeu a composição nutricional e a produção do rabanete;

2. O efluente tratado elevou a razão de adsorção de sódio e porcentagem de sódio trocável do solo, mas sem risco de sodificação;

3. O rabanete apresentou contaminação microbiológica em termos de coliformes totais e E. coli, em desacordo com a legislação sanitária vigente.

\section{AGRADECIMENTOS}

À FAPESP (Fundação de Amparo à Pesquisa do Estado de São Paulo) - Processo 2010/20081-7 e ao CNPQ (Conselho Nacional de Desenvolvimento Científico e Tecnológico) - Processo 474409/2010-4.

\section{REFERÊNCIAS BIBLIOGRÁFICAS}

ABREU, I.M.O.; JUNQUEIRA, A.M.R.; PEIXOTO, J.R.; OLIVEIRA, S.A. Qualidade microbiológica e produtividade de alface sob adubação química e orgânica. Revista Ciência e Tecnologia de Alimentos, v.30, p.108-118, Suplemento 1, 2010.

APHA - American Public Health Association. Standard methods for the examination of water and wastewater. 21.ed. Washington: APHA, 2005.1082p.

ASSISTAT 7.7 Beta. Assistência Estátistica. Responsável Dr. Francisco de Assis Santos e Silva. DEAG-CTRN-UFCG, Campina Grande - PB, Brasil. Registro INPI 0004051-2. Disponível em: $<$ http://assistat.com/indexp.html $>$. Acesso em: 28 out. 2014.

AYERS, R.S.; WESTCOT, D.W. A qualidade da água na agricultura. Estudos FAO: Irrigação e Drenagem, 29 Revisado 1. 2.ed. Campina Grande: UFPB, 1999. 153p.

BAKHSH. K.; HASSAN, S. Use of sewage water for radish cultivation: a case study of Punjab, Pakistan. Journal of Agriculture \& Social Sciences v.1, p.322-326, 2005.

BARRETO, A.N.; NASCIMENTO, J.J.V.R.; MEDEIROS, E.P.; NÓBREGA, J.A.; BEZERRA, J.R.C. Changes in chemical attributes of a fluvent cultivated with castor bean and irrigated with wastewater. Revista Brasileira de Engenharia Agrícola e Ambiental, v.17, p.480-486, 2013.

BAUMGARTNER, D.; SAMPAIO, S.C.; SILVA, T.R.; TEO, C.R.P.A.; VILAS BOAS, M. A. Reuso de águas residuárias da piscicultura e da suinocultura na irrigação da cultura da alface. Revista de Engenharia Agrícola, v. 27, n.1, p. 152-163, 2007.

BRASIL. Resolução ANVISA - RDC n. ${ }^{\circ}$ 12, de 2 de janeiro de 2001. Aprova o regulamento 
técnico sobre padrões microbiológicos para alimentos, e dá outras providências. Diário Oficial da União, Brasília, 2001. p.1-67.

CETESB - Companhia de Tecnologia Ambiental do Estado de São Paulo. Instrução técnica n.32. Orientação para apresentação de projeto visando à aplicação de água de reuso proveniente de estação de tratamento de esgoto doméstico na agricultura. São Paulo: CETESB, 2006. 11p.

EMBRAPA - Empresa Brasileira de Pesquisa Agropecuária - Manual de análises químicas de solos, plantas e fertilizantes. 2.ed. Brasília: EMBRAPA, 2009. 627p.

KHURANA, M.P.S.; SINGH, P. Waste water use in crop production: A review- resources and environment, v.2, p.116-131, 2012.

MEDEIROS, S. S.; SOARES, A. A.; FERREIRA, P. A.; NEVES, J. C. L.; MATOS, A. T \& SOUZA, J. A. A. Utilização de água residuária de origem doméstica na agricultura: Estudo das alterações químicas do solo. Rev. Brasileira de Engenharia Agrícola e Ambiental. v. 9, n. 4, p. 603-612, 2005.

OLIVEIRA, P.C.P.; GLOAGUEN, T.V.; GONÇALVES, R.A.B.; SANTOS, D.L. Produção de moranga irrigada com esgoto doméstico tratado. Revista Brasileira de Engenharia Agrícola e Ambiental, v.17, p.861-867, 2013.

PEREIRA, E.R.; PIEDADE, S.M.S. Crescimento do rabanete em túneis baixos cobertos com plástico perfurado em diferentes níveis de perfuração. Revista Thesis, v. 2, p.32- 44, 2004.

RIBEIRO, E.A.; SANDRI, D.; BOÊNO, J.A. Qualidade da água de córrego em função do lançamento de efluente de abate de bovino. Revista Brasileira de Engenharia Agrícola e Ambiental, v.17, p.425-433, 2013.
ROCHA, R.E.M.; PIMENTEL, M.S.; ZAGO, V.C.P.; RUMJANEK, N.G.; DE-POLLI, H. Avaliação de biossólido de águas servidas domiciliares como adubo em couve. Pesquisa Agropecuária Brasileira, v.38, p.1435-1441, 2003.

SANDRI, D.; MATSURA, E.E.; TESTEZLAF, R. Alteração química do solo irrigado por aspersão e gotejamento subterrâneo e superficial com água residuária. Revista Brasileira de Engenharia Agrícola e Ambiental, v.13, p.775-764, 2009.

STEEL, R.G.D.; TORRIE, J.H.; DICKEY, D. Principles and procedures of statistics: a biometrical approach. 3.ed. New York: McGraw-Hill, 1997. 666p.

TAKAYANAGUI, O.M.; CAPUANO, D.M.; OLIVEIRA, C.A.D.; BERGAMINI, A.M.M.; OKINO, M.H.T.; CASTRO e SILVA, A.A.M.C.; OLIVEIRA, M.A.; RIBEIRO, E. G.A.; TAKAYANAGUI, A.M.M. Análise da cadeia de produção de verduras em Ribeirão Preto (SP). Revista Sociedade Brasileira de Medicina Tropical, v. 39, n. 2, p. 224-226, 2006.

TEÓFILO, T.M.S.; FREITAS, F.C.L.; NEGREIROS, M.Z.; LOPES, W.A.; VIEIRA, S.S. Crescimento de cultivares de cenoura nas condições de Mossoró, RN. Revista Caatinga, v.22, p.168-174, 2009.

TRANI, F.E.; PASSOS, F.A.; TAVARES, M.; AZEVEDO FILHO, J.A. Beterraba, cenoura, nabo, rabanete e salsa. In: RAIJ, B. VAN; CANTARELLA, H.; QUAGGIO, J.A.; FURLANI, M.C. Recomendações de adubação e calagem para o Estado de São Paulo. 2.ed. Campinas: IAC, 1997. 285p. Boletim, 100.

VARALLO, A.C.T.; SOUZA, J.M.; REZENDE, S.S.R.; SOUZA, C.F. Avaliação da qualidade sanitária da alface (Lactuca sativa, 
L.) irrigada com água de reuso comparada com amostras comercializadas. Revista Ambiente \& Água, v.6, p.295-304, 2011.

VON SPERLING, M. Princípios do Tratamento Biológico de Águas Residuárias Volume 3 -Lagoas de estabilização. Departamento de Engenharia Sanitária e Ambiental. Universidade Federal de Minas Gerais. 1996. 140p.

WALKER, D.J. ; BERNAL, M.P. The effects of olive mill waste compost and poultry manure on the availability and plant uptake of nutrients in a highly saline soil. Bioresource Technology, v.99, p.396 403, 2008.

ZAR, J.H. Biostatistical Analysis. 5.ed. New York: Pearson, 2010. 960p.

ZAVADIL, J. The Effect of municipal wastewater irrigation on the yield and quality of vegetables and crops. Soil and Water Research, v.4, p.91-103, 2009. 